Published in final edited form as:

J Vasc Interv Radiol. 2015 May ; 26(5): 613-624. doi:10.1016/j.jvir.2015.01.017.

\title{
Bariatric Embolization of the Gastric Arteries for the Treatment of Obesity
}

Clifford R. Weiss, MD ${ }^{1,}{ }^{\star}$, Andrew J. Gunn, MD ${ }^{1}$, Charles Y. Kim, MD ${ }^{2}$, Ben E. Paxton, MD $^{3}$, Dara L. Kraitchman, VMD, $\mathbf{P h D}^{4,5}$, and Aravind Arepally, $\mathbf{M D}^{6}$

${ }^{1}$ Vascular and Interventional Radiology Center, Russell H. Morgan Department of Radiology and Radiological Science, The Johns Hopkins Hospital/The Johns Hopkins University; Baltimore, MD 21287

${ }^{2}$ Vascular and Interventional Radiology, Duke University Medical Center; Durham, NC 27710

${ }^{3}$ Interventional Radiology, Yavapai Regional Medical Center, Prescott, AZ

${ }^{4}$ Division of MR Research, Russell H. Morgan Department of Radiology and Radiological

Science, Johns Hopkins Hospital/Johns Hopkins University; Baltimore, MD 21287

${ }^{5}$ Department of Molecular and Comparative Pathobiology, The Johns Hopkins University; Baltimore, MD 21287

${ }^{6}$ Division of Interventional Radiology, Piedmont Radiology; Atlanta, GA 30309

\begin{abstract}
Obesity is a public health epidemic in the United States, which results in significant morbidity, mortality, and cost to the healthcare system. Despite advancements in therapeutic options for the bariatric patients, the number of overweight and obese individuals continues to rise. Thus, complimentary or alternative treatments to lifestyle changes and surgery are urgently needed. Embolization of the left gastric artery, or 'bariatric arterial embolization', has been shown to modulate body weight in animal models and early clinical studies. If successful, bariatric arterial embolization represents a potential minimally invasive approach to treat obesity offered by interventional radiologists. The purpose of the following review will be to introduce the interventional radiologist to bariatric arterial embolization by presenting its physiologic and anatomic bases, reviewing the pre-clinical and clinical data, and discussing current and future investigations.
\end{abstract}

\section{Keywords}

obesity; ghrelin; embolization; left gastric artery; bariatric

(C) 2015 SIR. All rights reserved.

*Corresponding author: Clifford R. Weiss, MD, Vascular and Interventional Radiology Center, The Johns Hopkins Hospital, Sheikh Zayed Tower, Suite 7203, 1800 Orleans St, Baltimore, MD 21287, Phone: 410-614-0601, Fax: 410-955-0233, cweiss@ jhmi.edu.

Publisher's Disclaimer: This is a PDF file of an unedited manuscript that has been accepted for publication. As a service to our customers we are providing this early version of the manuscript. The manuscript will undergo copyediting, typesetting, and review of the resulting proof before it is published in its final citable form. Please note that during the production process errors may be discovered which could affect the content, and all legal disclaimers that apply to the journal pertain. 


\section{Introduction}

There has been a significant increase in the number of obese individuals in the United States over the last twenty years (1) (Figure 1). It is estimated that currently nearly two-thirds of American adults are overweight, obese, or morbidly obese $(2,3)$. A multitude of factors have fueled the obesity epidemic including: sedentary lifestyles, poor portion control, and the increased availability of high-calorie foods (1). Regardless of the cause, obesity is now a major driver of morbidity and mortality in the United States due to its well-known associations with degenerative joint disease, liver disease, stroke, heart disease, type II diabetes, obstructive sleep apnea, hyperlipidemia, phlebitis, gout, polycystic ovarian syndrome, infertility, and even cancer (1). Moreover, this potentially preventable condition costs the American health care system nearly $\$ 168$ billion annually and accounts for approximately $16.5 \%$ of all expenditures (4).

The existing therapeutic strategy for patients with obesity and obesity-related health conditions involves maximizing lifestyle modifications (e.g., diet and exercise) and medical management. More aggressive therapies, such as bariatric surgery, are typically reserved for patients with a body mass index (BMI) of $>40 \mathrm{~kg} / \mathrm{m}^{2}$ or a BMI of $>35 \mathrm{~kg} / \mathrm{m}^{2}$ with an obesityrelated comorbid condition who have failed more conservative measures (5). While there are several bariatric surgical techniques, Roux-En-Y gastric bypass (RYGB), sleeve gastrectomy (SG), and adjustable gastric banding (AGB) are the most commonly employed (6)(Figure 2). Multiple randomized studies have found that surgical intervention for obesity results in greater weight loss with more improvements in obesity-related health conditions than non-surgical interventions, with the largest efficacy seen with the most aggressive surgery, RYGB (7). Unfortunately, surgical interventions for obesity have significant morbidity and mortality with post-operative anastamotic leak (0.1-5.6\%), intussusception (1\%), gallstones (13-36\%), and operative revisions (39-81\%) being the most common complications after RYGB (6). These procedures are also expensive; bariatric surgery patients are charged, on average, $\sim \$ 38,254$ and, if complications occur, these costs can rise to $\sim \$ 64,000(8,9)$. Therefore, less invasive therapies that could also target earlier stages of obesity are warranted. One minimally invasive technique that could potentially be provided by the interventional radiologist is percutaneous, catheter-directed, trans-arterial embolization of the left gastric artery (LGA), which we have termed 'Bariatric Arterial Embolization' (BAE). The purpose of this article will be to introduce the interventional radiologist to BAE by presenting its physiologic and anatomic bases, reviewing the preclinical and clinical data, and discussing current and future investigations.

\section{Rationale for bariatric arterial embolization}

The neuroendocrine functions of the gastrointestinal (GI) tract in regulating energy expenditure and metabolic homeostasis are well-known but have become the focus of scientific interest in light of the global obesity epidemic. Presently, numerous studies have confirmed that the success of bariatric surgery is not entirely related to the nutrient/volume restriction but is dependent upon its profound physiologic effect (both the endocrine and neuronal in nature) $(10,11)$. In fact, one of the most dramatic effects of bariatric surgery is the significant glucose lowering and reversal of diabetes that is seen within days of surgery 
prior to any effective weight loss (12). Hence, as a result of this positive metabolic profile, bariatric surgery is often referred as "metabolic surgery". Consequently, interventions to mimic these alteration in hormonal production is an area of intensive research to treat obesity and the underlying rational and basis for bariatric arterial embolization.

The following section will serve as a brief introduction to the neuroendocrine function of the GI tract by highlighting its signaling pathways and the major hormones involved the regulation of metabolic homeostasis.

\section{Neuroendocrine signals between the gastrointestinal tract and central nervous system (Table 1)}

The neuroendocrine signals involved in metabolic homeostasis that arise from the GI tract can generally be categorized as either long-acting or short-acting; although, it should be noted that some GI-produced hormones can induce both long- and short-acting effects (13). Long-acting signals have an important role in maintaining body weight by controlling energy expenditure and fat metabolism while short-acting signals typically regulate the initiation of meals via the feeling of hunger and the termination of meals from a feeling of 'fullness'. These regulatory signals from the GI tract reach the central nervous system (CNS) predominantly via two main pathways (14) (Figure 3). The first pathway transmits afferent signals from GI tract to the medulla by way of the vagus nerve while the second pathway involves the release of GI-produced hormones into the bloodstream, which, after traveling to the CNS, directly activate receptors in the brain. Of note, some of the hormones of the GI tract use both pathways in order to communicate with the CNS. Finally, changes in the concentrations of these gut hormones, such as glucagon-like peptide-1 (GLP-1), gastric inhibitory polypeptide (GIP), peptide YY (PYY), oxyntomodulin, cholecystokinin, and ghrelin, have been shown to change significantly after bariatric surgery, particularly RYGB and SG.

\section{Cholecystokinin (CCK)}

CCK is primarily produced by mucosal cells of the duodenum and jejunum in response to ingested food (15). It primarily functions to promote satiety by delaying gastric emptying in addition to stimulating pancreatic enzyme secretion and gallbladder wall contractions through the activation of CCK-A receptors (13-16). Clinical investigations into the use of CCK and CCK-A receptor agonists as a therapeutic alternative for obese patients have been unsuccessful to-date, potentially due to its short-lived anorectic effects $(15,17)$. Patients who have undergone bariatric surgery have demonstrated postoperative elevations of CCK concentrations with the largest increase in patients undergoing RYGB versus sleeve gastrectomy(18).

\section{Peptide $\mathrm{YY}_{\text {3-36 }}$}

$\mathrm{PYY}_{3-36}$ is the bioactive form of PYY, which is released from the mucosa of the small bowel in response to ingested food (15). It is believed, but not definitively known, that $\mathrm{PYY}_{3-36}$ also induces satiety by delaying gastric emptying. Clinical studies investigating the infusion of $\mathrm{PYY}_{3-36}$ as a means to combat obesity have had variable results. For example, 
one study found that the peripheral infusion of $\mathrm{PYY}_{3-36}$ reduced caloric intake in both lean and obese patients by up to $31 \%$ (19). Other reports, however, have demonstrated variable effects of $\mathrm{PYY}_{3-36}$ infusion on caloric intake based upon the dose, route, and timing of infusion (15). More recent data also have shown that meal-stimulated PYY secretions increase significantly for up to one year after bariatric surgery

\section{Leptin}

Leptin is a hormone produced by adipocytes that binds receptors in the CNS and inhibits hunger signals. Circulating levels of leptin are associated with amount of peripheral fat stores and plasma levels of leptin have been shown to decline in response to reductions in body fat (20). Studies have shown that some obese individuals have either mutations in the leptin gene or leptin receptor, leading to hyperphagia and weight gain (20). There is a strong suggestion that leptin decreases after RYGB and that it is associated with anthropometric measurements. These findings are consistent with the concept that leptin is secreted in proportion to body fat mass.(21)

\section{Glucagon-like peptide-1}

GLP-1 is produced by the L cells of the distal small bowel and colon in response to ingested food (15) and has been regarded as the "ileal brake" with regards to food intake. GLP-1 imparts satiety through activations of receptors in the vagus nerve, proximal GI tract, pancreas, brainstem, and hypothalamus (15). In addition, the effect of GLP-1 secretion is multi-faceted including delay of gastric emptying, increased insulin secretion, decreased gastric acid secretion, and decreased glucagon secretion (21). Often, the largest change in gut hormone secretion after RYGP or sleeve gastrectomy is the significant rise in peripheral GLP-1 within days after surgery. It is this dramatic rise in GLP-1 that is implicated in improving beta-cell function and the resolution of type 2 diabetes in patients who have undergone bariatric surgery (29).

\section{Ghrelin}

Ghrelin is a 28 amino acid peptide whose structure and function were initially described by Kojima et al (30). It is found in highest concentrations within the fundus of the stomach, where nearly three-quarters of the body's ghrelin is produced. Secondary sites of production include the duodenum, pancreas, ovaries, adrenal cortex, and the brain (13). Ghrelin has a unique function in regard to the initiation of meals and the maintenance of metabolic homeostasis as it is the only known orexigenic, or appetite-stimulating, hormone (Figure 4). After release, ghrelin induces hunger, increases GI motility, and suppresses insulin production through activation of both vagally mediated pathways and receptors in the hypothalamus $(13,15,30)$. Plasma levels of ghrelin have been shown to rise significantly before meals and to decrease after meals $(15,31)$. Moreover, the intravenous administration of ghrelin resulted in nearly half of healthy volunteers describing a sensation of hunger with a compensatory $28 \%$ increase in caloric intake $(28+/-3.9 \% \mathrm{p}<0.001)(32)(33)$. Plasma ghrelin levels also negatively correlate with body mass index (BMI), increase in overweight individuals during a weight-loss program, and decrease in anorexia nervosa patients who undergo recovery and subsequent weight gain (34). 


\section{Ghrelin: an exciting target for obesity}

Ghrelin is an intriguing prospective therapeutic target in the bariatric population due to its potent orexigenic effects and singular role in the short- and long-acting regulation of body weight. Potential pharmacologic interventions aimed at ghrelin production or receptor binding have been previously suggested (35). First, given that ghrelin is produced from a precursor peptide called preproghrelin, one could attempt to modify or interrupt the cleavage process in an effort to reduce plasma ghrelin levels. Second, one could attempt to produce an artificial mimic of ghrelin that competes for vagal and/or hypothalamic receptors in order to block the effects of plasma ghrelin. It was proposed by Hamilton et al that such interventions could potentially lead to weight loss, although developing such drugs would require a significant investment in time and cost. Furthermore, the obese patient would almost certainly be permanently dependent upon such a medication in order to maintain weight loss.

There is also evidence to suggest that ghrelin may actually play a role in patient weight loss after bariatric surgery. In a small study, Cummings et al found that obese subjects who lost a massive amount of weight after RYGB (on average $36 \%$ of pre-operative weight) experienced a significant decrease in plasma ghrelin levels compared to matched obese controls who underwent a dietary program $(\mathrm{p}=0.01)$, even though one would generally expect ghrelin levels to increase with weight loss (31). Multiple subsequent investigations since Cummings' initial observation of paradoxically decreased ghrelin levels after RYGB have shown that post-procedural ghrelin levels can be decreased, the same, or even increased when compared to pre-operative values (36-38). Potential explanations behind these heterogeneous results may be found in differences in surgical technique, such as: the size of the created gastric pouch, size of the gastro-jejunal stoma, length of the Roux limb, length of the pancreaticobiliary limb, location of the staple line in the gastric fundus, sparing of the vagus nerve, or the creation of vertical (rather than horizontal) gastric pouch $(38,39)$. Regardless, ghrelin's potential to induce weight loss either in connection with, as an adjunct to, or independently from bariatric surgery certainly warrants further investigation, especially given the invasiveness, cost, and recovery involved with bariatric surgery.

\section{Bariatric Arterial Embolization: a new approach to treat obesity}

The stomach is classically separated into five major sections: cardia, fundus, body, antrum, and pylorus (Figure 5A). While each section of the stomach has a unique role in the digestive process, the fundus serves as the epicenter for the neuroregulatory pathways involved with satiety and appetite stimulation (40-42). Ghrelin is expressed mainly in the fundus, containing 10 to 20 times more ghrelin per gram of tissue than the duodenum, which is the next richest source (13).

Anatomically, the vascular supply to the gastric fundus is predominantly and reliably from the left gastric artery (Figure 5B) and can be accessed with a catheter from a trans-arterial approach (Figure 6)(43-45). Percutaneous trans-arterial embolization of the upper GI arteries for bleeding is a minimally-invasive procedure, which is routinely performed by interventional radiologists on both an in-patient and out-patient basis, and is generally well- 
tolerated given the rich collateral vascular supply to the GI tract. Therefore, it has been theorized that embolization of the LGA could induce sufficient ischemia to the mucosa of the gastric fundus to inhibit ghrelin production by cells which, in turn, could lead to weight loss. This novel therapeutic approach could lead to a role for the interventional radiologist in the bariatric population.

\section{Bariatric Arterial Embolization: pre-clinical studies}

Arepally et al (46) were the first to explore the possibility of BAE. In their pilot study, eight healthy swine underwent angiography of the gastric vessels in order to identify all fundal vessels, including the LGA. Six swine underwent BAE with morrhuate sodium, a sclerosing agent, while two of the swine underwent sham embolization with normal saline. The dose of morrhuate sodium ranged from $37.5 \mu \mathrm{g}-2000 \mu \mathrm{g}$. After the procedure, the swine were fed $a d$ libitum. Sham embolization resulted in no significant difference between pre-procedural and post-procedural serum ghrelin levels $(\mathrm{p}=0.51$ ) nor any significant weight loss. Animals that received the lowest doses of morrhuate sodium during BAE (37.5-62.5 $\mu \mathrm{g})$ showed an unexpected increase in serum ghrelin levels $(\mathrm{p}=0.002)$. The authors postulated that an incomplete embolization of the fundal gastric mucosa may have negated the inhibitory feedback on the production of ghrelin. Animals who received $125 \mu \mathrm{g}$ of morrhuate sodium during BAE demonstrated a decrease in serum ghrelin levels. The single swine that received the highest dose $(2000 \mu \mathrm{g})$ during BAE died on post-procedure day \#1 from a ruptured gastric ulcer. Despite the variable changes seen in serum ghrelin levels after these initial BAEs, the authors could not demonstrate any significant weight loss in the experimental animals during the study period ( $p>0.05$ ). Histopathologic analysis of the gastric mucosa of the experimental animals showed a decrease in tissue ghrelin, overall preserved tissue architecture, and micro-ulcers at the gastro-esophageal junction (which were assumed to be secondary to non-target embolization of the distal esophageal branches of the LGA). This early pilot study was the first to demonstrate that serum ghrelin levels could be modulated via $\mathrm{BAE}$ and laid the foundation for further investigation into the topic by establishing a reference dose of the sclerosing agent.

Arepally et al (47) subsequently evaluated the ability of BAE, which they termed 'gastric artery chemical embolization' or 'GACE', to suppress serum ghrelin levels and modulate weight in ten healthy swine using a standard dose of morrhuate sodium $(125 \mu \mathrm{g})$. Again, each animal underwent diagnostic angiography in order to identify all fundal vessels. Half of the animals in this study underwent BAE while the other half underwent sham embolization with normal saline. Animals were all fed ad libitum post-procedurally. In this study, BAE resulted in a significant drop in plasma ghrelin levels over the study period (pre-procedure: $1006.3 \mathrm{pg} / \mathrm{dL}$; post-procedure average: $684.3 \mathrm{pg} / \mathrm{dL}$ ) while animals that underwent sham embolization did not show any significant change in plasma ghrelin levels (pre-procedure: $1078 \mathrm{pg} / \mathrm{dL}$; post-procedure: $1104 \mathrm{pg} / \mathrm{dL}$ ) (Figure 7). Overall the pattern of change of ghrelin levels was significantly different between control and treated animals $(\mathrm{p}<0.004)$. Plasma ghrelin levels decreased each week after BAE for the first three weeks but rose closer to pre-procedural levels at the fourth week $(876.6 \mathrm{pg} / \mathrm{dL})$. This is of note because follow-up angiography performed at this same time point after BAE demonstrated that the fundal vessels had re-established patency, suggesting that the increase in serum ghrelin 
levels may be the result of re-established fundal flow. Furthermore, growing juvenile pigs that underwent BAE gained less weight (7.8\% relative to pre-procedure) than control animals (15\%, p <0.04), (Figure 7). These findings provided further support that this minimally-invasive procedure was able to modulate weight and potentially could be used to treat obesity.

Although the initial animal studies exploring BAE used morrhuate sodium to occlude the LGA $(46,47)$, there are a variety of other clinically available embolic materials that could be employed, such as other sclerosants, coils, particles, or gelfoam. Subsequently, Bawudun et al (48) evaluated both a liquid sclerosant (bleomycin $\mathrm{A}_{5}$ hydrochloride (BAH) emulsified with lipiodol ultrafluid) and 500-700 $\mu \mathrm{m}$ polyvinyl alcohol (PVA) particles as embolic agents in a canine model to assess changes in serum ghrelin levels, body weight, and body fat composition. Alterations to these parameters were assessed in three distinct groups: a BAH embolization arm, a PVA particle arm, and a control arm (sham embolization with normal saline). The dogs were fed a fixed caloric diet based upon their body weight after the procedure. Body fat area was quantified by computed tomography (CT) prior to the procedure and eight weeks after the procedure. Animals experienced a $15.8 \%$ and $30.2 \%$ decrease in serum ghrelin levels after BAE with BAH and PVA particles, respectively, which was significant compared to the $13.6 \%$ increase in serum ghrelin levels seen in the control group (BAH p=0.007, PVA $\mathrm{p}=0.004$ ). Both experimental arms showed an equivalent decrease in the amount of both subcutaneous and overall fat area by $\mathrm{CT}$, which was significantly greater than the control group (BAH $\mathrm{p}=0.011$, PVA $\mathrm{p}=0.027$ ). Finally, both experimental arms (BAH and PVA) demonstrated a significant amount of weight loss after the procedure (BAH $\mathrm{p}=0.000$, PVA $\mathrm{p}=0.000$ ), with weight loss directly correlated to serum ghrelin levels. Importantly, the authors reported no clinically significant adverse events in any of the test animals or any evidence of gastric mucosal ulceration on histopathologic analysis.

One advantage of liquid embolics, such as BAH and morrhuate sodium, is their ability to penetrate deeply into the smallest of capillaries. Unfortunately, many liquid embolic are known to be very caustic, which can result in tissue damage. Moreover, the potential for damage from non-target embolization is significant. Thus, the next step in the advancement of BAE toward a clinical model was finding a clinically available embolic agent. To this end, calibrated microspheres have the benefit of being able to pass into smaller caliber vessels than the larger PVA particles, which can range from 300-1000 $\mu \mathrm{m}$. Microspheres could also theoretically provide long-term occlusion to fundal vessels (as opposed to a nonpermanent agent like gelfoam). Using this rationale, Paxton et al (49) performed BAE in growing swine using clinically available $40 \mu \mathrm{m}$ microspheres (CeloNova Biosciences; San Antonio, Texas) mixed with equal parts of nonionic contrast (Isovue 300; Bracco Diagnostics, Seattle, WA)) in the experimental group. Control animals underwent embolization of the fundal vessels with normal saline. After the procedure, the swine were fed a fixed caloric diet base on weight. Animals that underwent BAE experienced a significant decrease in serum ghrelin levels (pre-procedure: $1605.7 \mathrm{pg} / \mathrm{dL}$; post-procedure: $1067.8 \mathrm{pg} / \mathrm{dL}$ ) compared to the control group (pre-procedure: $1591.6 \mathrm{pg} / \mathrm{dL}$; post-procedure: $1920.5 \mathrm{pg} / \mathrm{dL})(\mathrm{p}=0.004)$ (49). Moreover, the animals that underwent BAE gained, on 
average, $3.8 \mathrm{~kg}$ over the study period which was significantly less than the $9.4 \mathrm{~kg}$ increase seen in the control group ( $\mathrm{p}=0.025$ ) (Figure 8).

After sacrifice of these animals at eight weeks, a gross pathologic examination, traditional hematoxylin and eosin staining, and a immunohistochemical analysis of the gastric mucosa and duodenum was performed (50). Approximately half of treated animals had evidence of gastric ulceration in the gastric body (not the fundus) ranging from $1.2-7.9 \mathrm{~cm}$ in maximal diameter. No full thickness ulcers were identified and all ulcers were either healed or healing at the time of evaluation. Most importantly, there was no evidence of fundal mucosal ulceration in any treated animal. The gastric body ulceration in these animals may have been the result of non-target embolization since small amounts of embolic particles were identified in the gastric antrum and body. Alternatively, it is known that swine get gastroesophageal ulcers during periods of stress (51); thus, the ulceration seen by Paxton et al may be more related to peri-procedural stress than non-target embolization - especially in light of the high incidence of gastritis in the sham animals in this study. While mucosal ulceration is an unwanted effect, the excellent healing response observed in this study without prophylactic therapy or post-procedural intervention is encouraging and may indicate that particle embolization-induced ulcers are mild and transient without significant long-term sequelae.

Immunohistochemical analysis of the gastric and duodenal mucosa demonstrated that the number of ghrelin-producing cells per high-powered field was significantly lower in the BAE group than in the control group $(\mathrm{p}<0.01)$ (Figure 9) Also, there was no change in the number of ghrelin producing cells in the duodenum between control and experimental arms suggesting that there was no up-regulation of these cells in the non-embolized duodenum $(\mathrm{p}=0.89)$. Finally, the authors also noted increased fibrosis $(\mathrm{p}=0.07)$ within the gastric fundus and decreased acid producing cells in the non-embolized antrum ( $\mathrm{p}=0.03)$, which may result in delayed gastric emptying in post-BAE swine. These findings highlight potential secondary affects of BAE (through the alteration of gastric motility and absorption), which may work synergistically with hormonal changes to promote weight loss.

\section{Bariatric Arterial Embolization: early clinical data}

Clinical investigations of BAE in patients have just begun with limited clinical data. Recently, Gunn et al (52) performed a single-center, retrospective analysis of patients, who underwent embolization of the LGA for gastrointestinal bleeding. In this limited retrospective study spanning twelve years, the weights of the adult patients who underwent LGA embolization for upper GI bleeding were compared to patients who underwent embolization of any other branch off the celiac axis for upper GI bleeding. Additionally, potentially confounding factors (left ventricular ejection fraction, serum creatinine, history of malignancy, and chemotherapy) during the study period were also reviewed. In this small study (19 patients were in the experimental group and 28 patients were in the control group), patients that underwent LGA embolization lost, on average, $7.3 \%$ of their body weight versus the $2 \%$ weight loss observed in the control group at the same time point postembolization $(\mathrm{p}=0.006)$. However, this study is significantly limited by its retrospective 
nature as well as the potential overlap of multiple confounding factors that can be seen during the inpatient management of a variety of disorders.

To-date, there has been only one reported prospective experience with BAE (53). This small study included five patients with different degrees of obesity who underwent BAE using 300-500 $\mu \mathrm{m}$ microspheres (Biocompatibles UK Limited; Surrey, UK). In addition to endoscopy, this study evaluated serum ghrelin levels at weeks 1 to 4 . Three of five patients experienced abdominal discomfort immediately after the procedure but follow-up endoscopy demonstrated no gastric ulcers. The mean weight changed from a baseline of $128.1+/-24.4$ $\mathrm{kg}$ to $107.6+/-22.7 \mathrm{~kg}(\mathrm{p}<0.05)$. In addition, serum ghrelin showed a significant drop (up to $30 \%$ from baseline, $\mathrm{p}<0.05)$ at three months analogous to the preclinical studies performed by Arepally et al (49). Endoscopy found no significant alterations to the stomach mucosa and no peri-procedural complications.

\section{Current investigations and future directions}

Despite promising pre-clinical and early clinical data, there are many unanswered questions that require investigation before BAE can be routinely offered to bariatric patients. For example, the complicated vascular anatomy of the stomach and its rich supply of collateral vessels creates a technical challenge to administer either small particle or liquid embolics without non-target embolization and resultant tissue damage in a population of patients without a terminal illness. Therefore, the development of methodologies and devices that allow for more accurate catheter placement or prevent the distribution of embolic material to non-target areas would have the effect of increasing the safety profile of BAE. Recently, Weiss et al (54) suggested three potential solutions to these technical obstacles: 1) intraprocedural C-arm cone beam CT (CBCT) to better localize the distribution of embolic material, 2) barium sulfate-containing $50 \mu \mathrm{m}$ alginate beads that can be visualized directly under fluoroscopy during embolization to assess for reflux and/or non-target embolization, and 3) a $3 \mathrm{~F}$ anti-reflux microcatheter (Surefire MT ${ }^{\mathrm{TM}}$ ) composed of a unique valve with a microfilter coating that enables forward flow while dynamically preventing retrograde flow during infusion. These tools were evaluated in a porcine model of BAE where six animals underwent BAE while four animals underwent sham embolization. A pre-embolization digital subtracted angiogram (DSA) and a DSA CBCT were performed to evaluate the complicated vasculature and vessels supplying the porcine gastric fundus. Then, BAE was performed using the barium sulfate-impregnated $50 \mu \mathrm{m}$ beads through the anti-reflux microcatheter. Finally, a post-embolization DSA run and CBCT were repeated. All animals underwent endoscopy one week after the procedure with weekly monitoring of body weight and plasma ghrelin levels. Post-BAE animals gained significantly less weight $(\mathrm{p}<0.01)$ than control animals over the 4-week study period. The treated animals also had significantly lower levels of plasma ghrelin ( $\mathrm{p}<0.001)$ and significantly higher levels of serum GLP-1 $(\mathrm{p}<0.001)$ at each time point than did the controls. At post-procedural endoscopy, half of the post-BAE animals had superficial fundal ulcers, and all treated animals showed evidence of delayed gastric emptying. The authors concluded that their newly developed technologies did allow for safe and effective embolization of the gastric fundus with resultant modulation of serum ghrelin, GLP-1, and body weight. The elevated GLP-1 in concert with food retention in the experimental group suggested that BAE may also slow gastric emptying. 
While there has been long history of left gastric embolization for gastrointestinal bleeding, its use in the setting of obesity is considered off-label and would likely receive intense scrutiny by regulatory bodies. In fact, with any obesity intervention, the FDA has extensive oversight on the implementation of all new procedures/devices, and, thus, the utilization of a regulatory pathway is mandated at present for BAE. Recently, based on a consensus panel, the FDA has established guidelines to help investigators design clinical trials utilizing a benefit-risk model with a safety profile being the highest priority. Using this paradigm, a structured process is now in place that allows the investigation of any obesity intervention to move from a safety and efficacy trial with a small sample size to larger pivotal trial (55). To this end, we have begun enrolling patients in the Bariatric Embolization of the Arteries for Treatment of Obesity (BEAT Obesity) trial (56). This investigator initiated IDE, approved by the FDA, will enroll morbidly obese patients who meet strict study criteria that were jointly coordinated with the FDA for BAE. BEAT Obesity aims to initially enroll five patients with the primary outcome focused on 30 day safety data. Once cleared by the FDA this will be expanded to a larger 20-person trial with primary outcomes of 30-day safety and one-year effectiveness. The authors are aware of at least two other clinical trials for BAE that are under review or accepting patients. Both of these trials aim to enroll five patients with one-year safety and effectiveness as primary outcomes (57). After the establishment of an acceptable safety profile in patients, multi-center, prospective, controlled studies can then be initiated. Future work could assess a variety of questions, such as the most effective size of embolic particles, formal evaluation of gastric emptying after BAE, and the safety of bariatric surgery after BAE. Additionally, long-term follow-up of these patients will provide more insight into whether BAE can produce sustained weight-loss comparable to bariatric surgery or alternatively provide a bridge to bariatric surgery. Finally, as in surgical treatments to obesity, interventions, such as BAE, will require coordination with a team of physicians and scientists in endocrinology, nutrition, psychology, physical therapy, surgery, radiology etc. to provide tailored programs to enable long-term success at weight loss.

\section{Conclusion}

In pre-clinical studies, bariatric embolization appears to have a global effect on the function of the stomach. In addition to decreasing ghrelin production in the fundus, BAE also indirectly affects acid production, gastric motility, and possibly absorption. Thus, analogous to a sleeve gastrectomy, bariatric embolization appears to impact body weight through the synergetic effects of manipulating both the hormonal and physiological function of the stomach.

However, there is still a tremendous need to expand the current knowledge base for bariatric embolization. Due to a lack of clinical data, fundamental questions regarding embolization techniques, optimal targeting, improved understanding of the gastric vascular anatomy and/or the ideal patient candidates are still unanswered. Fortunately, the initiation of several prospective clinical trials should provide significant insight on the potential impact of this procedure.

A multidisciplinary approach to obesity employing nutritional interventions, psychological behavioral modifications, physical conditioning, as well as surgical/medical interventions 
are most likely to succeed in the treatment this global epidemic. With the success of bariatric surgery, there is now a tremendous interest in mimicking its metabolic benefits using less invasive and safer techniques. As such, bariatric embolization may represent the next evolution in bariatric interventions, as this procedure aims to directly modulate the neurohormonal axes of hunger. With further refinements of this procedure, the opportunity exists to develop the first image-guided therapy targeting obesity.

\section{References}

1. C.D.C. Centers for Disease Control and Prevention. [Accessed October 23, 2014] Adult obesity facts. 2014. Available at www.cdc.gov/obesity/data/adult.html

2. Ogden CL, Carroll MD, Flegal KM. High body mass index for age among US children and adolescents, 2003-2006. JAMA. 2008; 299(20):2401-5. [PubMed: 18505949]

3. Sturm R. Increases in morbid obesity in the USA: 2000-2005. Public Health. 2007; 121(7):492-6. [PubMed: 17399752]

4. Cawley J, Meyerhoefer C. The medical care costs of obesity: an instrumental variables approach. J Health Econ. 2012; 31(1):219-30. [PubMed: 22094013]

5. NIH conference. Gastrointestinal surgery for severe obesity. Consensus Development Conference Panel. Annals of internal medicine. 1991; 115(12):956-61. [PubMed: 1952493]

6. Baptista V, Wassef W. Bariatric procedures: an update on techniques, outcomes and complications. Curr Opin Gastroenterol. 2013; 29(6):684-93. [PubMed: 24100715]

7. Colquitt JL, Pickett K, Loveman E, Frampton GK. Surgery for weight loss in adults. Cochrane Database Syst Rev. 2014; 8:CD003641. [PubMed: 25105982]

8. Dumon KR, Murayama KM. Bariatric surgery outcomes. Surg Clin North Am. 2011; 91(6):131338. x. [PubMed: 22054156]

9. Encinosa WE, Bernard DM, Chen CC, Steiner CA. Healthcare utilization and outcomes after bariatric surgery. Med Care. 2006; 44(8):706-12. [PubMed: 16862031]

10. Beckman LM, Beckman TR, Earthman CP. Changes in gastrointestinal hormones and leptin after Roux-en-Y gastric bypass procedure: a review. Journal of the American Dietetic Association. 2010; 110(4):571-84. [PubMed: 20338283]

11. Chandarana K, Batterham RL. Shedding pounds after going under the knife: metabolic insights from cutting the gut. Nature medicine. 2012; 18(5):668-9.

12. Karra E, Yousseif A, Batterham RL. Mechanisms facilitating weight loss and resolution of type 2 diabetes following bariatric surgery. Trends in endocrinology and metabolism: TEM. 2010; 21(6): 337-44. [PubMed: 20133150]

13. Wren AM, Bloom SR. Gut hormones and appetite control. Gastroenterology. 2007; 132(6):211630. [PubMed: 17498507]

14. Ahima RS, Antwi DA. Brain regulation of appetite and satiety. Endocrinol Metab Clin North Am. 2008; 37(4):811-23. [PubMed: 19026933]

15. Cummings DE, Overduin J. Gastrointestinal regulation of food intake. J Clin Invest. 2007; 117(1): 13-23. [PubMed: 17200702]

16. Liebling DSEJ, Gibbs J, Smith GP. Intestinal satiety in rats. J Comp Physiol Psychol. 1975; 89(8): 955-65. [PubMed: 1184801]

17. West DB, Fey D, Woods SC. Cholecystokinin persistently suppresses meal size but not food intake in free-feeding rats. Am J Physiol. 1984; 246(5 Pt 2):R776-87. [PubMed: 6326618]

18. Peterli R, Steinert RE, Woelnerhanssen B, Peters T, Christoffel-Courtin C, Gass M, et al. Metabolic and hormonal changes after laparoscopic Roux-en-Y gastric bypass and sleeve gastrectomy: a randomized, prospective trial. Obesity surgery. 2012; 22(5):740-8. [PubMed: 22354457]

19. Batterham RL, Cohen MA, Ellis SM, Le Roux CW, Withers DJ, Frost GS, et al. Inhibition of food intake in obese subjects by peptide YY3-36. N Engl J Med. 2003; 349(10):941-8. [PubMed: 12954742] 
20. Ravussin Y, Leibel RL, Ferrante AW Jr. A Missing Link in Body Weight Homeostasis: The Catabolic Signal of the Overfed State. Cell metabolism. 2014; 20(4):565-72. [PubMed: 25295786]

21. Beckman LM, Beckman TR, Earthman CP. Changes in gastrointestinal hormones and leptin after Roux-en-Y gastric bypass procedure: a review. Journal of the American Dietetic Association. 2010; 110(4):571-84. [PubMed: 20338283]

22. Batterham RL, Le Roux CW, Cohen MA, Park AJ, Ellis SM, Patterson M, et al. Pancreatic polypeptide reduces appetite and food intake in humans. The Journal of clinical endocrinology and metabolism. 2003; 88(8):3989-92. [PubMed: 12915697]

23. Swarbrick MM, Stanhope KL, Austrheim-Smith IT, Van Loan MD, Ali MR, Wolfe BM, et al. Longitudinal changes in pancreatic and adipocyte hormones following Roux-en-Y gastric bypass surgery. Diabetologia. 2008; 51(10):1901-11. [PubMed: 18704364]

24. Campos GM, Rabl C, Havel PJ, Rao M, Schwarz JM, Schambelan M, et al. Changes in postprandial glucose and pancreatic hormones, and steady-state insulin and free fatty acids after gastric bypass surgery. Surgery for obesity and related diseases: official journal of the American Society for Bariatric Surgery. 2014; 10(1):1-8. [PubMed: 24209879]

25. Dimitriadis E, Daskalakis M, Kampa M, Peppe A, Papadakis JA, Melissas J. Alterations in gut hormones after laparoscopic sleeve gastrectomy: a prospective clinical and laboratory investigational study. Annals of surgery. 2013; 257(4):647-54. [PubMed: 23108120]

26. Baggio LL, Huang Q, Brown TJ, Drucker DJ. Oxyntomodulin and glucagon-like peptide-1 differentially regulate murine food intake and energy expenditure. Gastroenterology. 2004; 127(2): 546-58. [PubMed: 15300587]

27. Wynne K, Park AJ, Small CJ, Patterson M, Ellis SM, Murphy KG, et al. Subcutaneous oxyntomodulin reduces body weight in overweight and obese subjects: a double-blind, randomized, controlled trial. Diabetes. 2005; 54(8):2390-5. [PubMed: 16046306]

28. Hollander P, Maggs DG, Ruggles JA, Fineman M, Shen L, Kolterman OG, et al. Effect of pramlintide on weight in overweight and obese insulin-treated type 2 diabetes patients. Obes Res. 2004; 12(4):661-8. [PubMed: 15090634]

29. Madsbad S, Dirksen C, Holst JJ. Mechanisms of changes in glucose metabolism and bodyweight after bariatric surgery. The lancet Diabetes \& endocrinology. 2014; 2(2):152-64. [PubMed: 24622719]

30. Kojima M, Hosoda H, Date Y, Nakazato M, Matsuo H, Kangawa K. Ghrelin is a growth-hormonereleasing acylated peptide from stomach. Nature. 1999; 402(6762):656-60. [PubMed: 10604470]

31. Cummings DE, Weigle DS, Frayo RS, Breen PA, Ma MK, Dellinger EP, et al. Plasma ghrelin levels after diet-induced weight loss or gastric bypass surgery. The New England journal of medicine. 2002; 346(21):1623-30. [PubMed: 12023994]

32. Wren AM, Seal LJ, Cohen MA, Brynes AE, Frost GS, Murphy KG, et al. Ghrelin enhances appetite and increases food intake in humans. The Journal of clinical endocrinology and metabolism. 2001; 86(12):5992. [PubMed: 11739476]

33. Cummings DE, Purnell JQ, Frayo RS, Schmidova K, Wisse BE, Weigle DS. A preprandial rise in plasma ghrelin levels suggests a role in meal initiation in humans. Diabetes. 2001; 50(8):1714-9. [PubMed: 11473029]

34. Druce MR, Small CJ, Bloom SR. Minireview: Gut peptides regulating satiety. Endocrinology. 2004; 145(6):2660-5. [PubMed: 15044353]

35. Hamilton, EJ.; Gunn, AJ.; Hesketh, RL.; Oklu, R. Ghrelin busters: a novel approach to weight loss treatment; Presented at the 99th Annual Scientific Meeting of the Radiological Society of North America; Chicago, IL. December 1-6, 2013; 2013.

36. Geloneze B, Tambascia MA, Pilla VF, Geloneze SR, Repetto EM, Pareja JC. Ghrelin: a gut-brain hormone: effect of gastric bypass surgery. Obesity surgery. 2003; 13(1):17-22. [PubMed: 12630608]

37. Faraj M, Havel PJ, Phelis S, Blank D, Sniderman AD, Cianflone K. Plasma acylation-stimulating protein, adiponectin, leptin, and ghrelin before and after weight loss induced by gastric bypass surgery in morbidly obese subjects. The Journal of clinical endocrinology and metabolism. 2003; 88(4):1594-602. [PubMed: 12679444] 
38. Pournaras DJ, Le Roux CW. The effect of bariatric surgery on gut hormones that alter appetite. Diabetes Metab. 2009; 35(6 Pt 2):508-12. [PubMed: 20152735]

39. Cummings DE, Shannon MH. Ghrelin and gastric bypass: is there a hormonal contribution to surgical weight loss? The Journal of clinical endocrinology and metabolism. 2003; 88(7):2999_ 3002. [PubMed: 12843132]

40. Hu Z, Cha SH, van Haasteren G, Wang J, Lane MD. Effect of centrally administered C75, a fatty acid synthase inhibitor, on ghrelin secretion and its downstream effects. Proc Natl Acad Sci U S A. 2005; 102(11):3972-7. [PubMed: 15728730]

41. Murray CD, Kamm MA, Bloom SR, Emmanuel AV. Ghrelin for the gastroenterologist: history and potential. Gastroenterology. 2003; 125(5):1492-502. [PubMed: 14598266]

42. Strader AD, Woods SC. Gastrointestinal hormones and food intake. Gastroenterology. 2005; 128(1):175-91. [PubMed: 15633135]

43. Miyaki A, Imamura K, Kobayashi R, Takami M, Matsumoto J, Takada Y. Preoperative assessment of perigastric vascular anatomy by multidetector computed tomography angiogram for laparoscopy-assisted gastrectomy. Langenbeck's archives of surgery / Deutsche Gesellschaft fur Chirurgie. 2012; 397(6):945-50.

44. Takeda FR, Cecconello I, Szachnowicz S, Tacconi MR, Gama-Rodrigues J. Anatomic study of gastric vascularization and its relationship to cervical gastroplasty. Journal of gastrointestinal surgery: official journal of the Society for Surgery of the Alimentary Tract. 2005; 9(1):132-7. [PubMed: 15623454]

45. Venieratos D, Panagouli E, Lolis E, Tsaraklis A, Skandalakis P. A morphometric study of the celiac trunk and review of the literature. Clinical anatomy. 2013; 26(6):741-50. [PubMed: 22886953]

46. Arepally A, Barnett BP, Montgomery E, Patel TH. Catheter-directed gastric artery chemical embolization for modulation of systemic ghrelin levels in a porcine model: initial experience. Radiology. 2007; 244(1):138-43. [PubMed: 17581899]

47. Arepally A, Barnett BP, Patel TH, Howland V, Boston RC, Kraitchman DL, et al. Catheterdirected gastric artery chemical embolization suppresses systemic ghrelin levels in porcine model. Radiology. 2008; 249(1):127-33. [PubMed: 18796671]

48. Bawudun D, Xing Y, Liu WY, Huang YJ, Ren WX, Ma M, et al. Ghrelin suppression and fat loss after left gastric artery embolization in canine model. Cardiovasc Intervent Radiol. 2012; 35(6): 1460-6. [PubMed: 22367009]

49. Paxton BE, Kim CY, Alley CL, Crow JH, Balmadrid B, Keith CG, et al. Bariatric embolization for suppression of the hunger hormone ghrelin in a porcine model. Radiology. 2013; 266(2):471-9. [PubMed: 23204538]

50. Paxton BE, Alley CL, Crow JH, Burchette J, Weiss CR, Kraitchman DL, et al. Histopathologic and immunohistochemical sequelae of bariatric embolization in a porcine model. J Vasc Interv Radiol. 2014; 25(3):455-61. [PubMed: 24462005]

51. Swaby H, Gregory NG. A note on the frequency of gastric ulcers detected during post-mortem examination at a pig abattoir. Meat Sci. 2012; 90(1):269-71. [PubMed: 21733635]

52. Gunn AJ, Oklu R. A preliminary observation of weight loss following left gastric artery embolization in humans. J Obes. 2014; 2014:185349. [PubMed: 25349724]

53. Kipshidze, N.; Archvadze, A.; Kantaria, M. First-in-man study of left gastric artery embolization for weight loss; Presented at the 62nd Annual Scientific Meeting of the American College of Cardiology; San Francisco, CA. March 10, 2013; 2013.

54. Weiss, CR.; Arepally, A.; Moran, TH.; Hu, C.; Singh, J.; Mao, HQ., et al. Effect of bariatric embolization on various appetite-driving hormones of obesity; Presented at the 30th Annual Scientific Meeting of the European Society of Interventional Radiology; Glasgow, UK. September 13-17, 2014; 2014.

55. Lerner H, Whang J, Nipper R. Benefit-risk paradigm for clinical trial design of obesity devices: FDA proposal. Surgical endoscopy. 2013; 27(3):702-7. [PubMed: 23247746]

56. http://clinicaltrials.gov/show/NCT02165124

57. https://clinicaltrials.gov/ct2/show/NCT02248688 

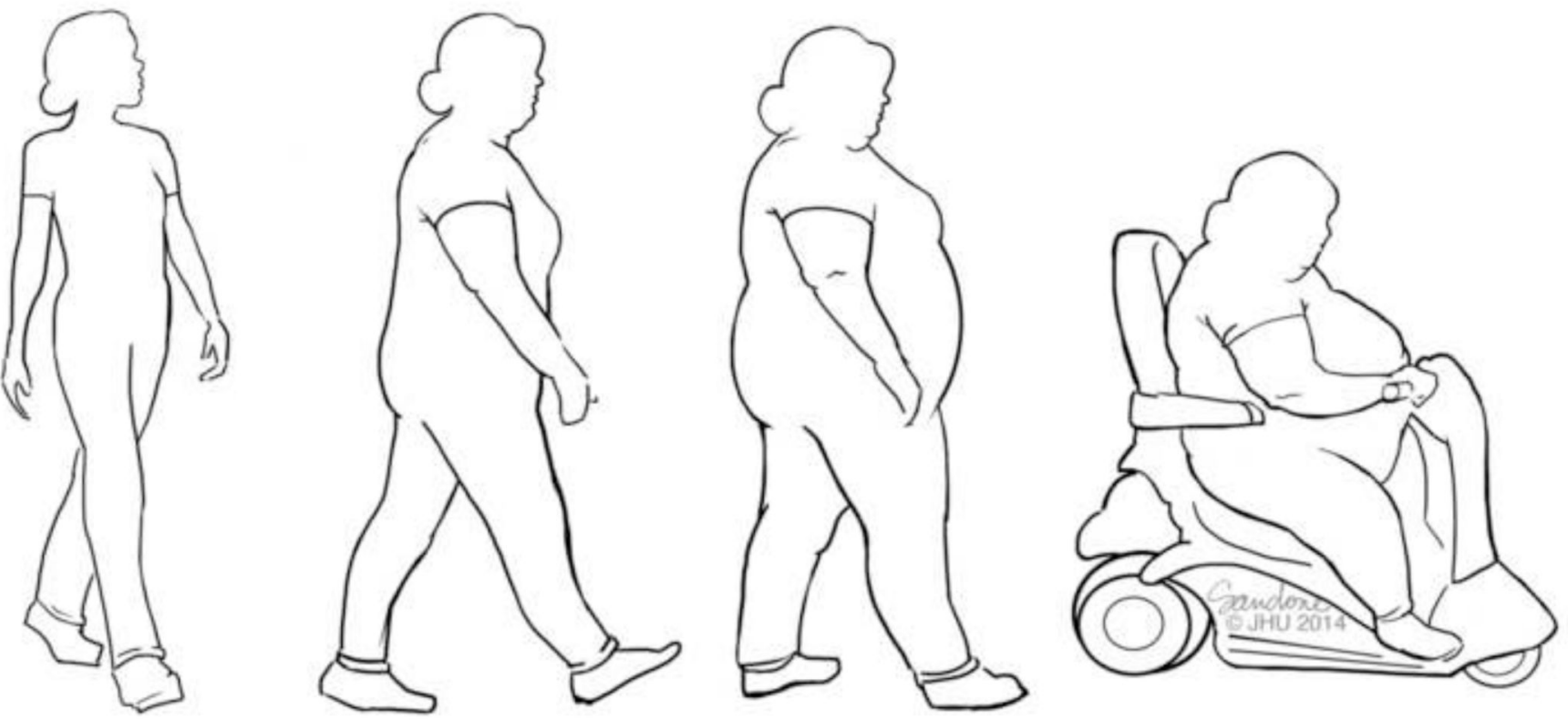

Normal

Overweight

Obese

Morbidly obese

Figure 1. Over the last 50 years, the United States population has been getting heavier, with a concomitant rise in obesity-related diseases (1)

- 1960-1962: 45.8\% of American adults were either overweight or obese (overweight: $31.5 \%$, obese: $13.4 \%$, extremely obese: $0.9 \%$ )

- 1976-1980: 48.5\% of American adults were either overweight or obese (overweight: $32.1 \%$, obese: $15 \%$, extremely obese: $1.4 \%$ )

- 1999-2000: 69.5\% of American adults were either overweight or obese (overweight: $33.6 \%$, obese: $30.9 \%$, extremely obese: $5 \%$ )

- 2005-2006: 73.5\% of American adults were either overweight or obese (overweight: $32.2 \%$, obese: $35.1 \%$, extremely obese: $6.2 \%$ )

- 2009-2010: 75.4\% of American adults were either overweight or obese (overweight: $32.7 \%$, obese: $36.1 \%$, extremely obese: $6.6 \%$ )

@Johns Hopkins University 


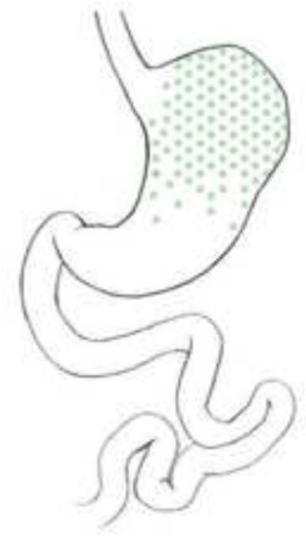

Normal Stomach

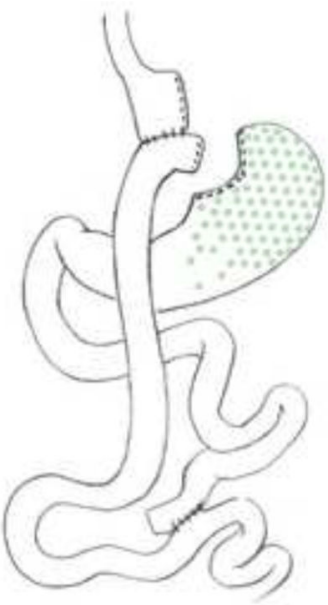

Roux-en-Y Gastric Bypass
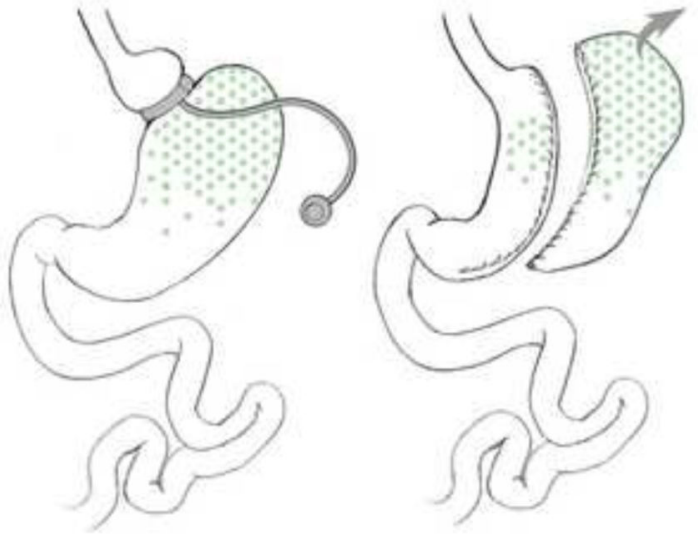

Adjustable Gastric Banding

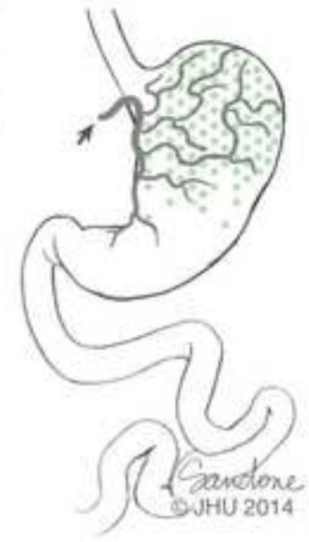

Bariatric

Arterial

Sleeve Gastrectomy

Figure 2. An overview of bariatric interventions

Roux-En-Y gastric bypass (RYGB), adjustable gastric banding (AGB), sleeve gastrectomy (SG) are the most commonly employed. The most effective is RYGB followed by SG, which may be in part due exclusion of ghrelin producing portions of the stomach (marked in green). Bariatric Arterial Embolization (BAE) is believed to cause weight loss due to ischemic changes to the gastric fundus, which causes decreased ghrelin production, as well as alterations in satiety hormones and in mechanical function (delayed gastric emptying). CJohns Hopkins University 


\section{Fasting vs. Fed}
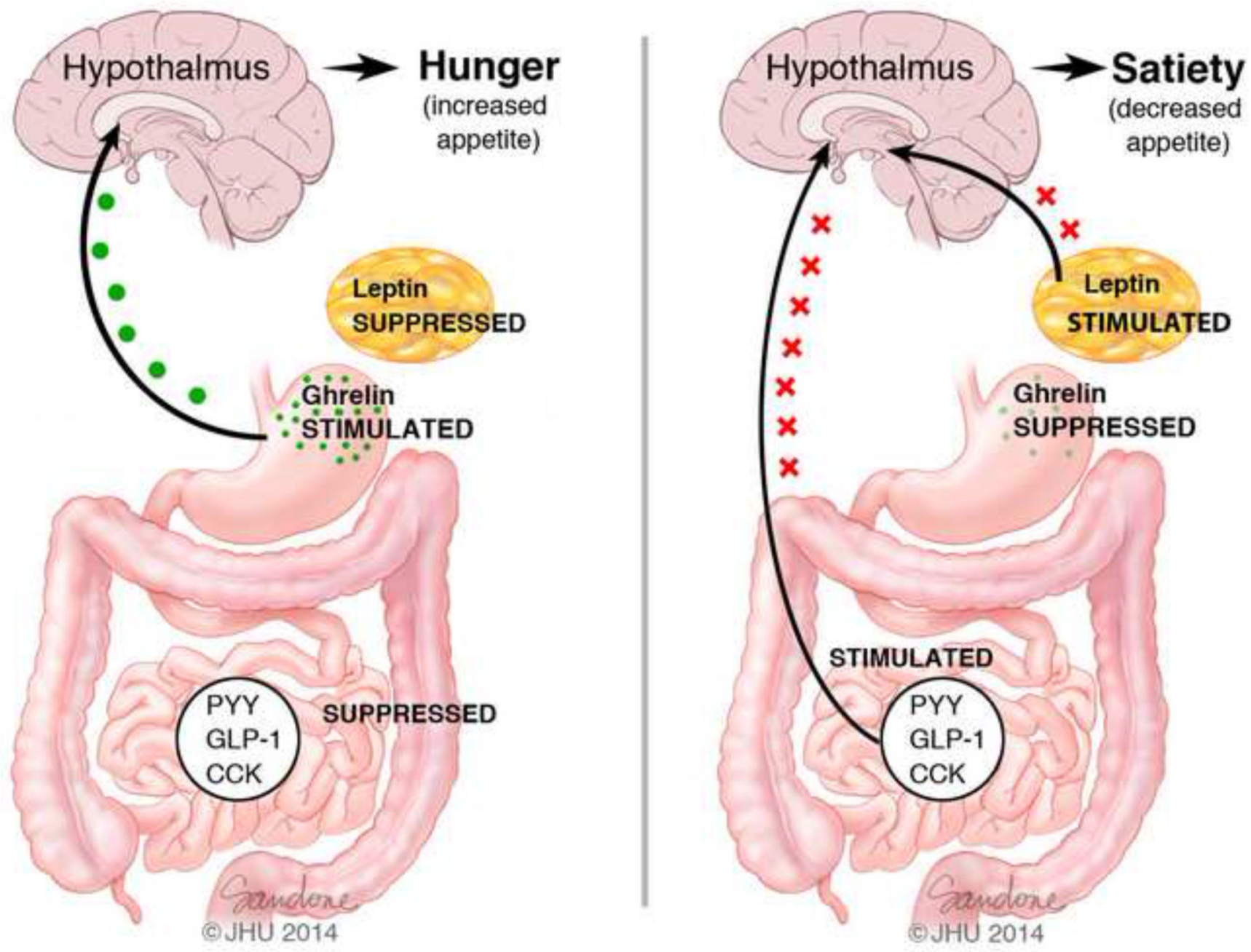

Figure 3. Hormonal changes during the Fasting vs. Fed States

Several hormones are released from the Gastrointestinal tract. The 'hunger hormone' ghrelin is secreted from X/A Cells in the gastric fundus, whereas PYY and GLP-1 are secreted from L cells, primarily from the ileum and colon. Leptin is primarily produced in adipocytes. During fasting, decreased food intake suppresses the release of PYY, GLP-1 and CCK from the gut while stimulating the secretion of ghrelin by the stomach. Fasting also decreases serum leptin levels. These changes are detected by the brain, leading to hunger. Dieting results in a gut hormone profile that mimics the fasted state. During and after regular feeding, there is a reduction in the production of ghrelin by the stomach. In contrast, production of PYY, GLP-1 and CCK from the gut is increased, and serum leptin levels also rise. These changes, which are detected by the brain, result in decreased appetite and a feeling of satiety.

CJohns Hopkins University 

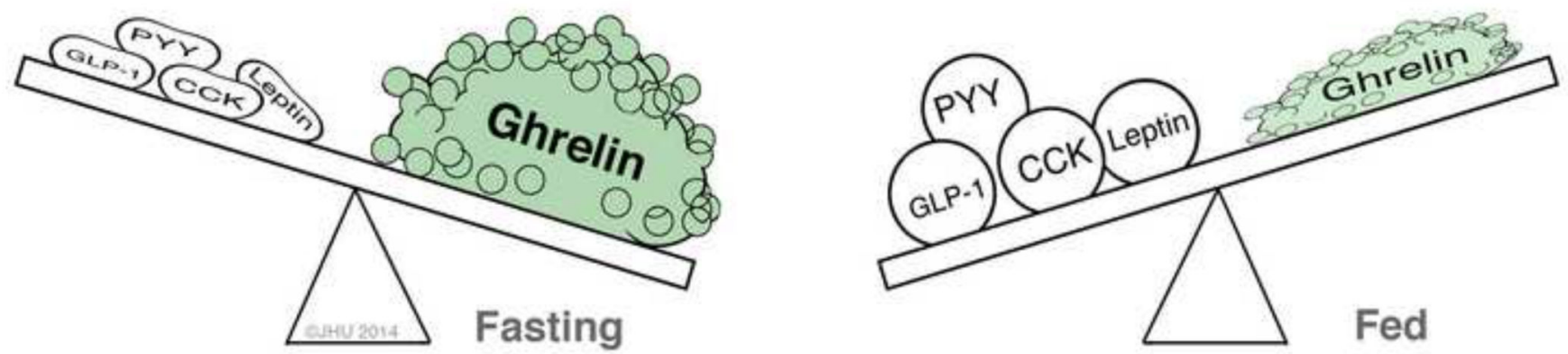

Figure 4. Hormonal balance in the fasting and fed states

Although there are many gastrointestinal hormones which promote satiety (e.g. PYY,

GLP-1, CCK and Leptin), only one, ghrelin is a potent orexigenic, or appetite-stimulating, hormone.

(C) Johns Hopkins University 

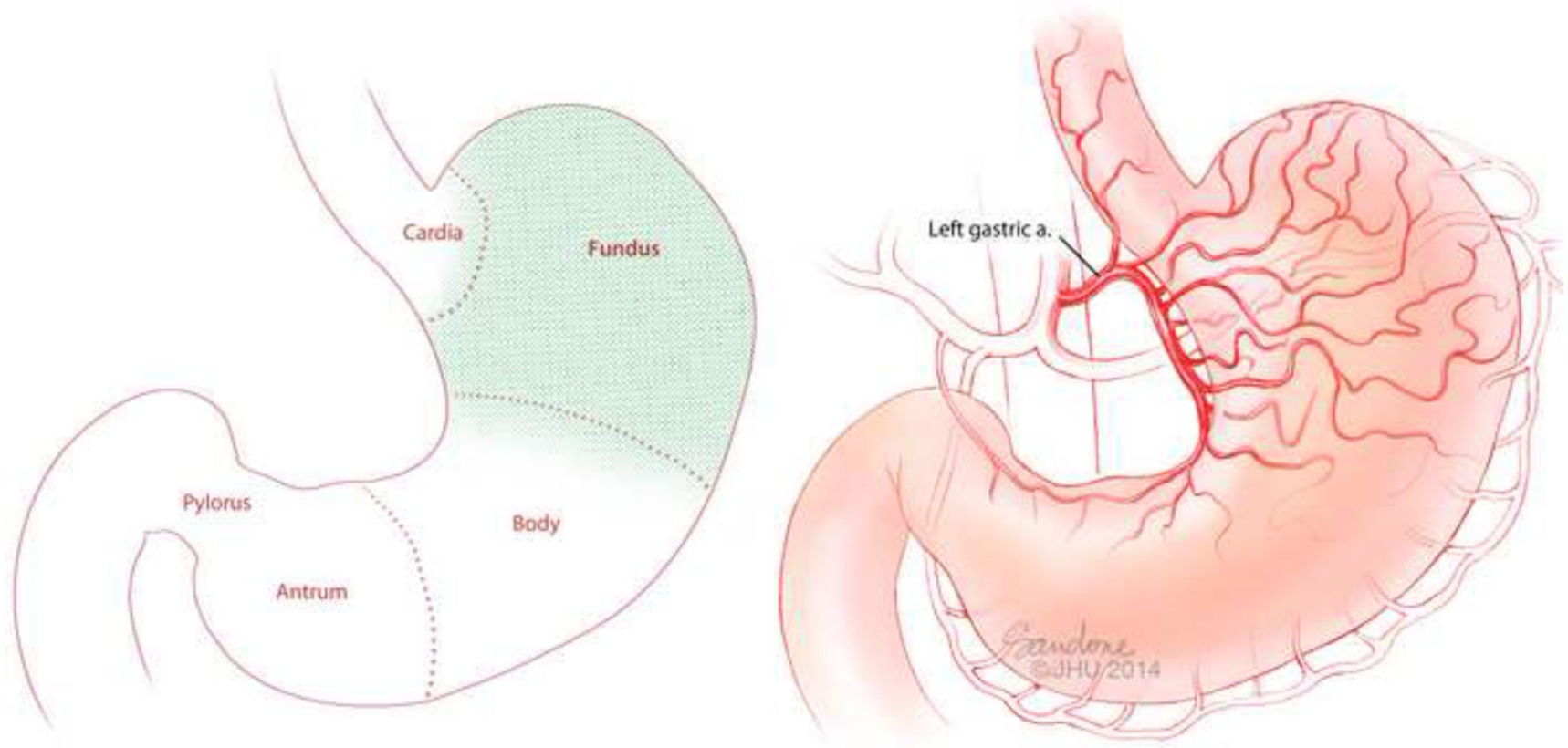

Figure 5. Basic gastric anatomy

(A) The stomach is divided generally into five anatomic/histologic sections: Cardia, Fundus, Body, Antrum and Pylorus. Ghrelin is produced by the X/A cells which exist predominately in the fundus (green shading). (B) The vascular supply to the fundus is primarily from the Left Gastric Artery.

@ Johns Hopkins University 


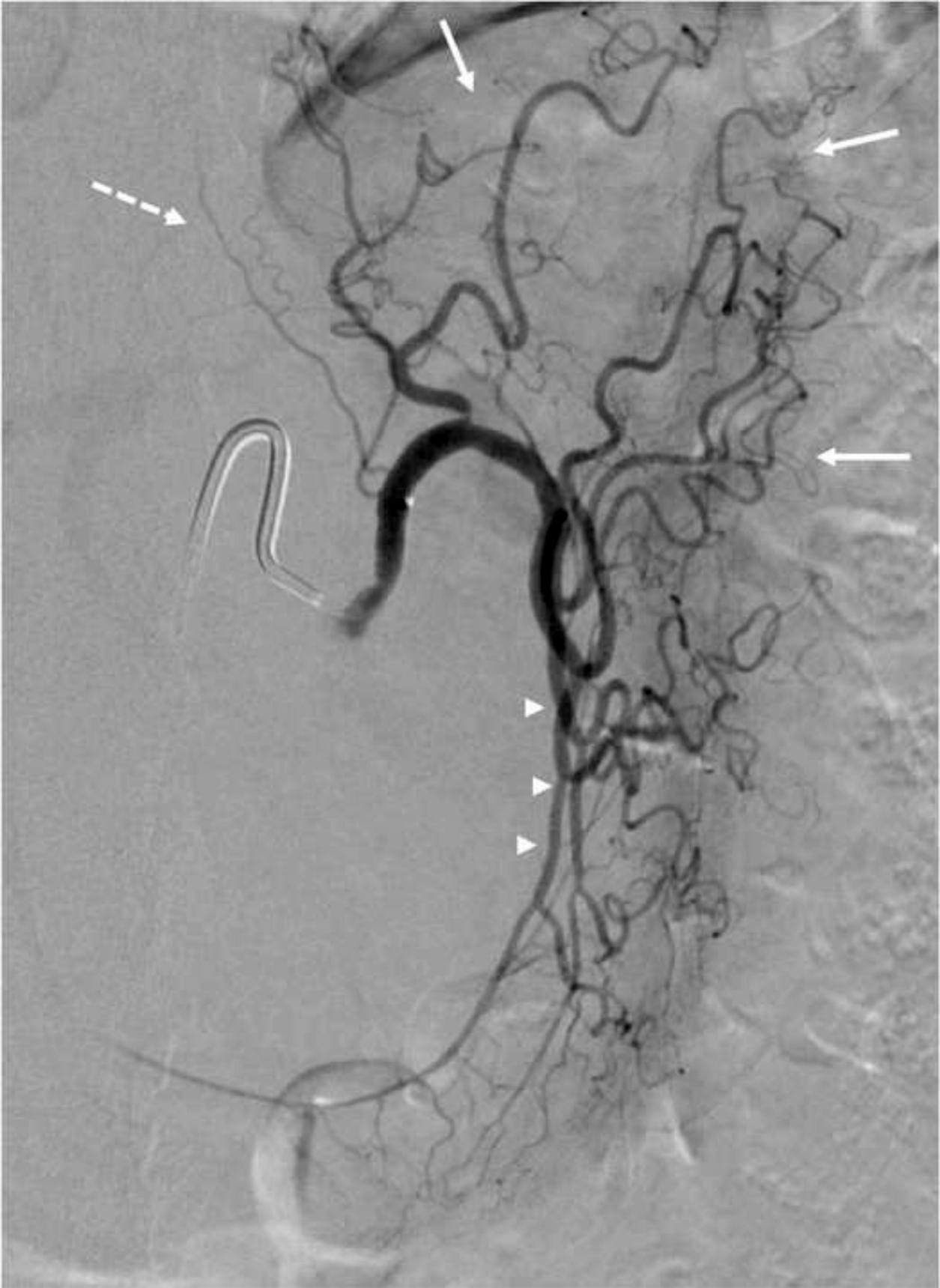

Figure 6. Digital Subtraction Angiogram (DSA) of the Left Gastric Artery

Left gastric artery selected using a 5F SOS-selective catheter and a high-flow microcatheter. Fundal (solid arrow) and esophageal (dashed arrow) branches are identified. This left gastric artery demonstrates a large anastomosis (arrowheads) with the right gastric artery along the lesser curvature.

(OJohns Hopkins University 


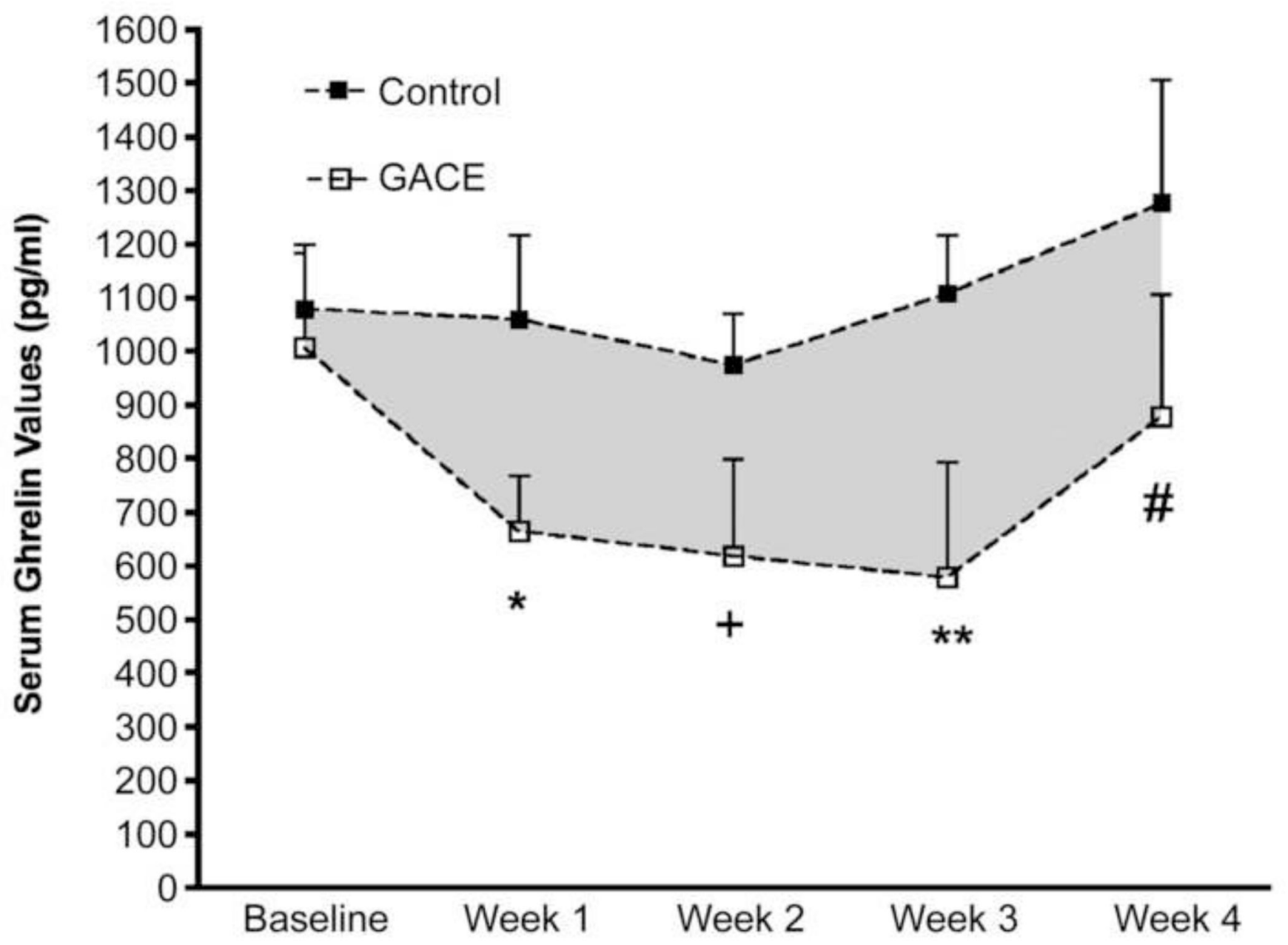




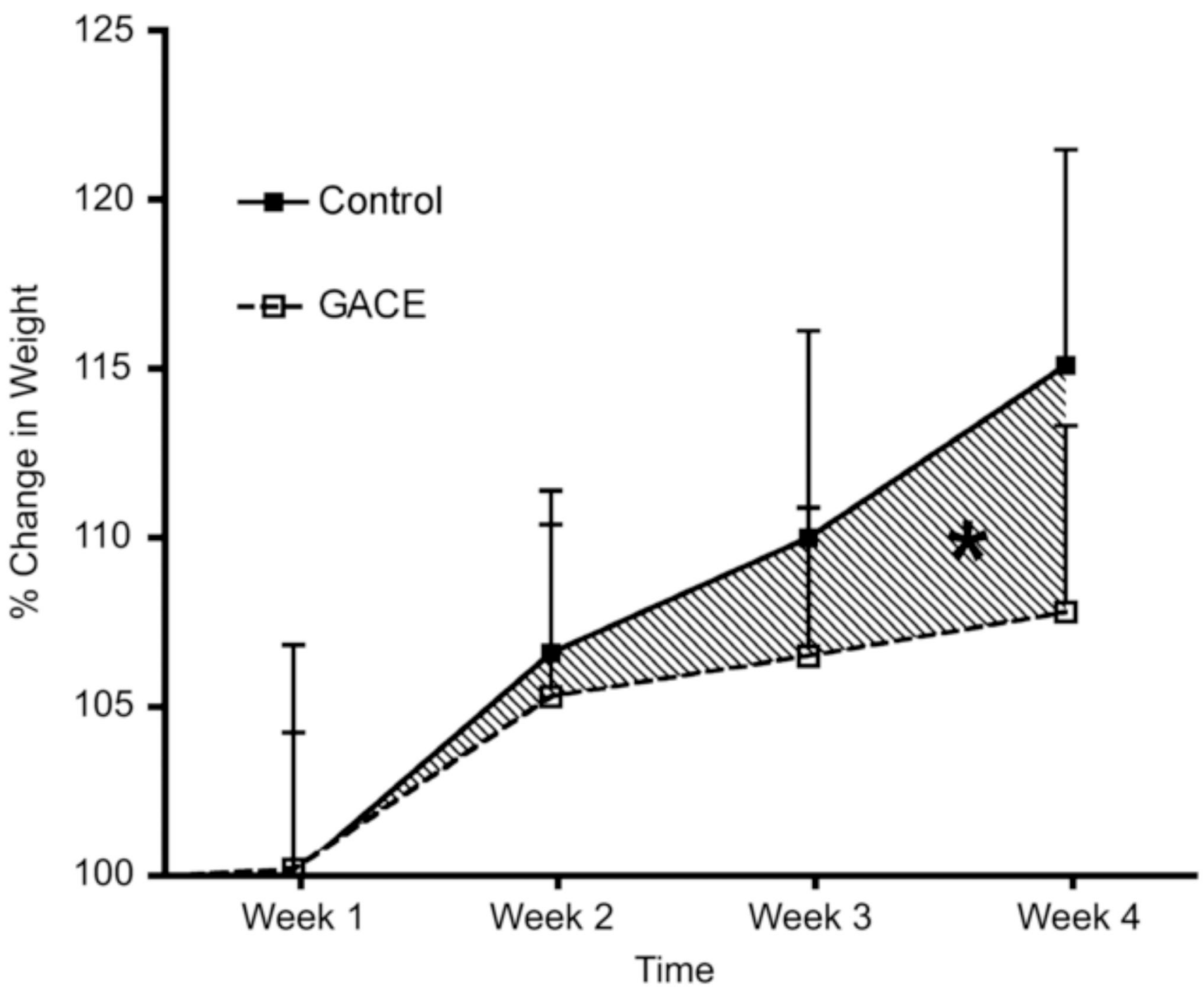

Figure 7. Ghrelin and Weight changes after catheter-directed Gastric Artery Chemical Embolization (GACE)

Reprinted with permission from Arepally A, Barnett BP, Patel TH, Howland V, Boston RC, Kraitchman DL, et al. Catheter-directed gastric artery chemical embolization suppresses systemic ghrelin levels in porcine model. Radiology. 2008;249(1):127-33.

(A) Graph shows mean ghrelin values in control and GACE-treated swine at baseline and at weeks $1-4$. The pattern of the change in ghrelin levels over time was significantly different between control and treated animals $(\mathrm{P}<.004) .{ }^{*}=\mathrm{P}<.02,+=\mathrm{P}<.001, * *=\mathrm{P}<.001$, \# = $\mathrm{P}<.03$ (ghrelin levels were significantly reduced at all time end points relative to baseline). Error bars $=$ standard errors of the mean. (B) Graph shows percentage change in weight over the 4-week period for control and GACE-treated swine. Control swine continued to grow over the time period, while GACE-treated swine plateaued in growth. The pattern of weight gain over 4 weeks was significantly different between GACE-treated and control swine. ${ }^{*}=$ $\mathrm{P}<.04$. Error bars=standard errors of the mean. 


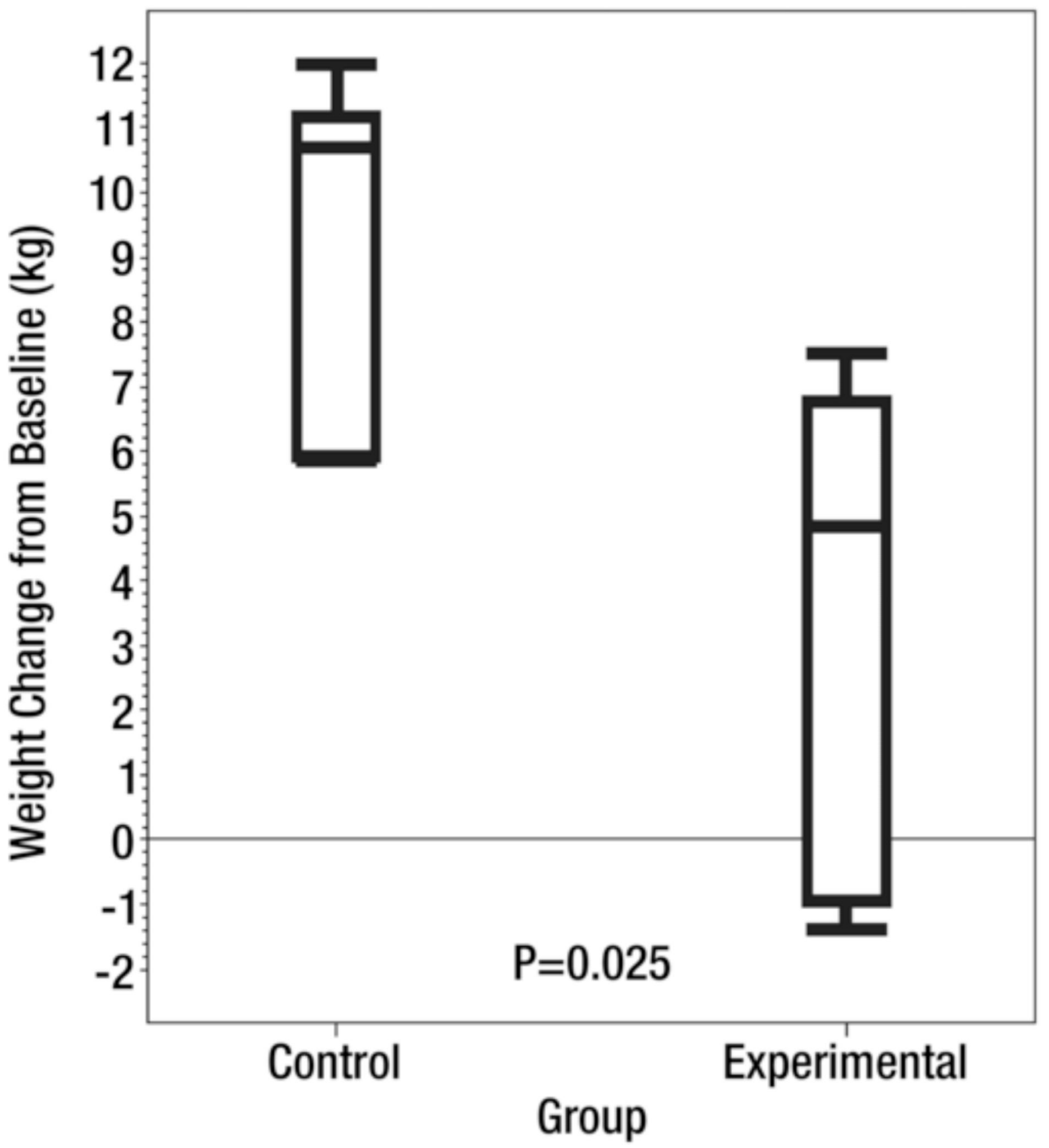

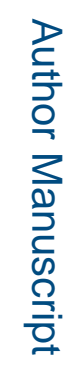




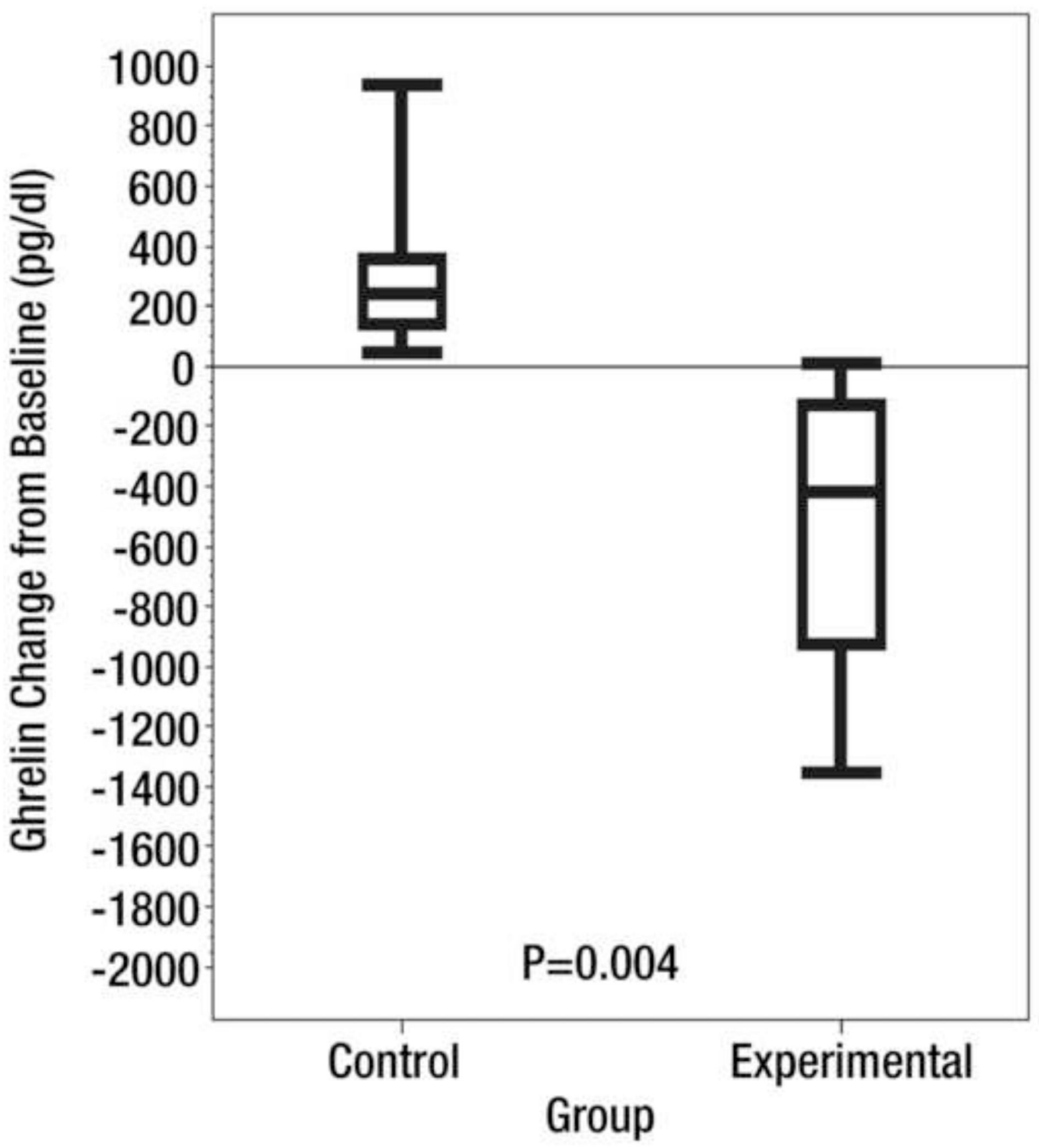

Figure 8. Ghrelin and Weight changes after Bariatric Arterial Embolization (BAE)

Reprinted with permission from: Paxton BE, Kim CY, Alley CL, Crow JH, Balmadrid B, Keith CG, et al. Bariatric embolization for suppression of the hunger hormone ghrelin in a porcine model. Radiology. 2013;266(2):471-9.

(A) Box plot shows mean serum ghrelin level change from baseline after the procedure (BAE) over the 8-week study in six control swine and six experimental BAE) swine. Bottom and top of boxes represent 25 th and 75 th percentiles, respectively. Horizontal line near the middle of boxes is the 50th percentile. Ends of whiskers represent sample minimum and 
maximum. (B) Box plot shows mean weight change from baseline after the procedure over the 8-week study in six control swine and six experimental swine. Bottom and top of boxes represent 25th and 75th percentiles, respectively. Horizontal line near the middle of the boxes is the 50th percentile. Ends of whiskers represent sample minimum and maximum. 


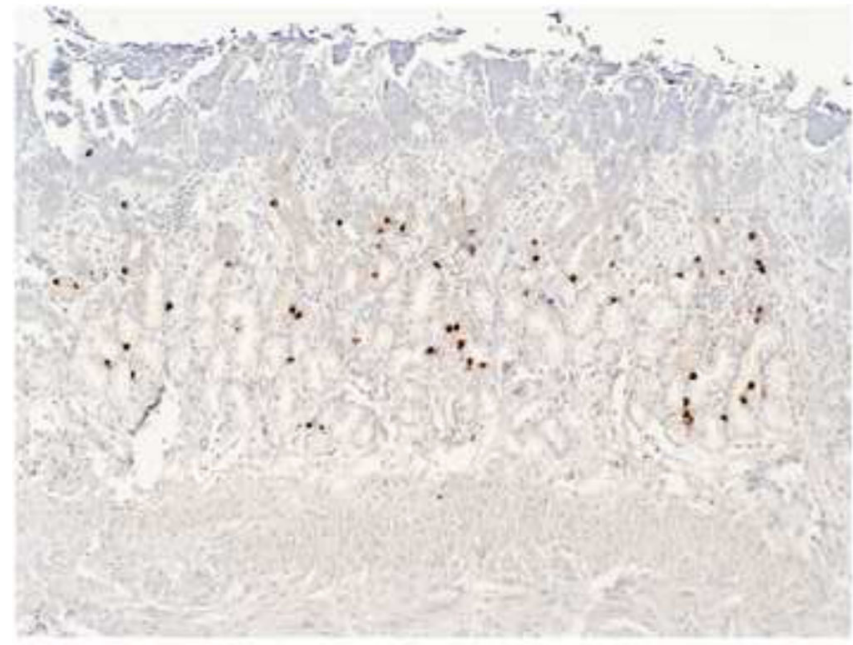

a.

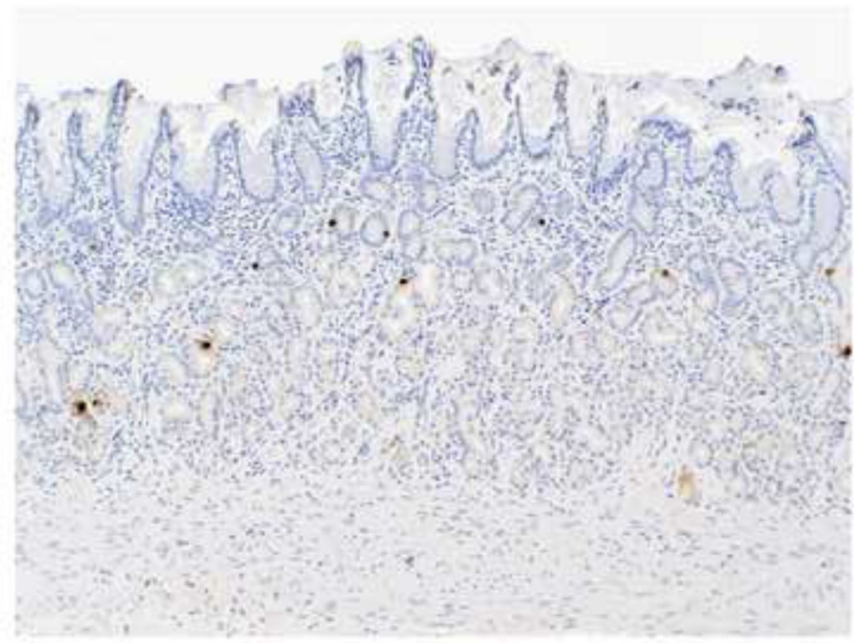

b. 


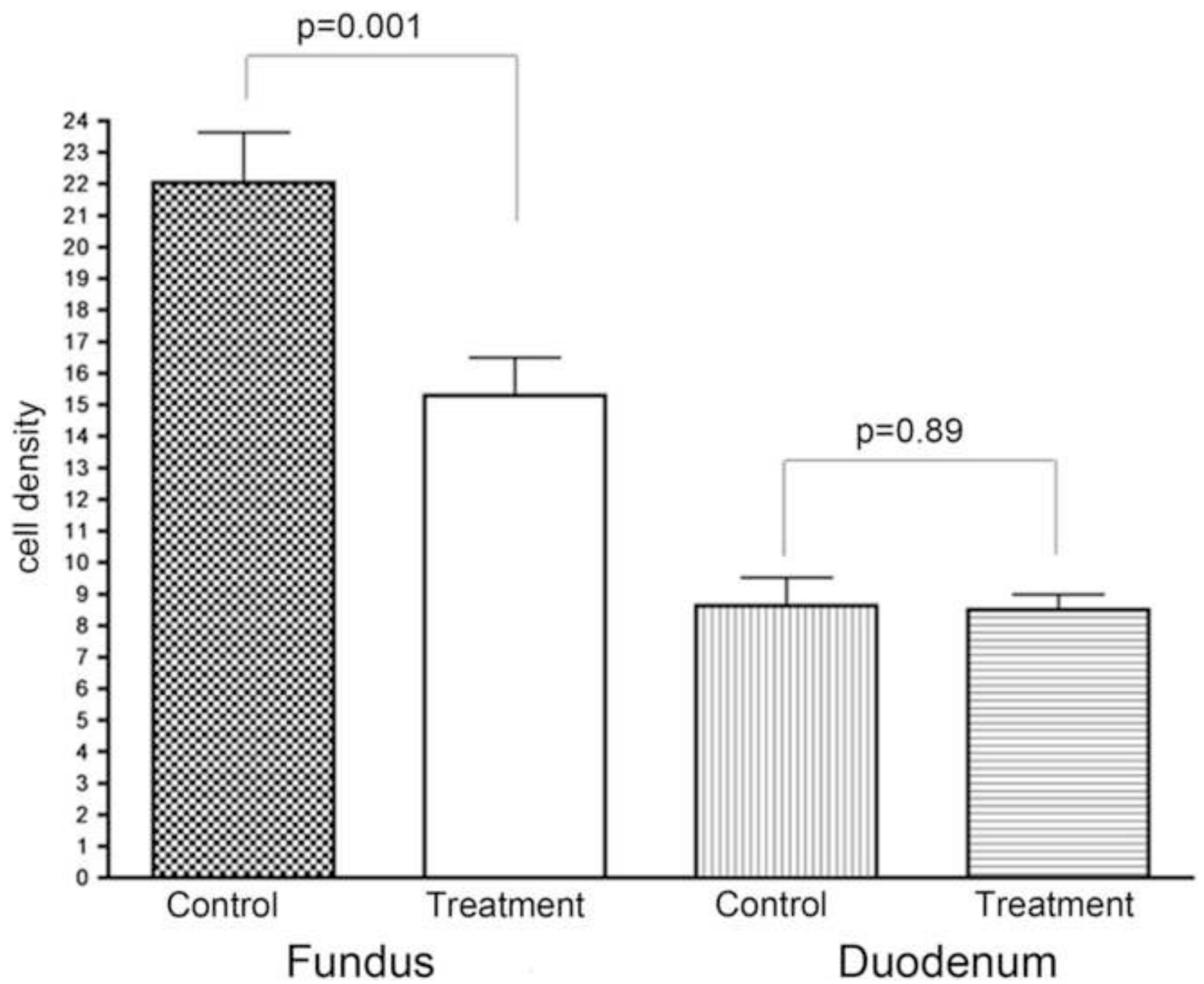

Figure 9. Histopathologic and immunohistochemical assessment of ghrelin production after Bariatric Arterial Embolization (BAE)

Reprinted with permission from: Paxton BE, Alley CL, Crow JH, Burchette J, Weiss CR, Kraitchman DL, et al. Histopathologic and immunohistochemical sequelae of bariatric embolization in a porcine model. J Vasc Interv Radiol. 2014;25(3):455-61.

Immunohistochemical staining of the gastric fundus for ghrelin-expressing cells $(\times 100)$. (A) Control animal shows multiple dark foci that represent ghrelin positivity. (B) Treatment animal shows decreased numbers of ghrelin-expressing cells. (C) Immunohistochemical staining of the gastric fundus and duodenum confirms a significant reduction in the ghrelinimmunoreactive cell density in the gastric fundus after embolization. There is no compensatory upregulation of ghrelin-expressing cells in the duodenum. 

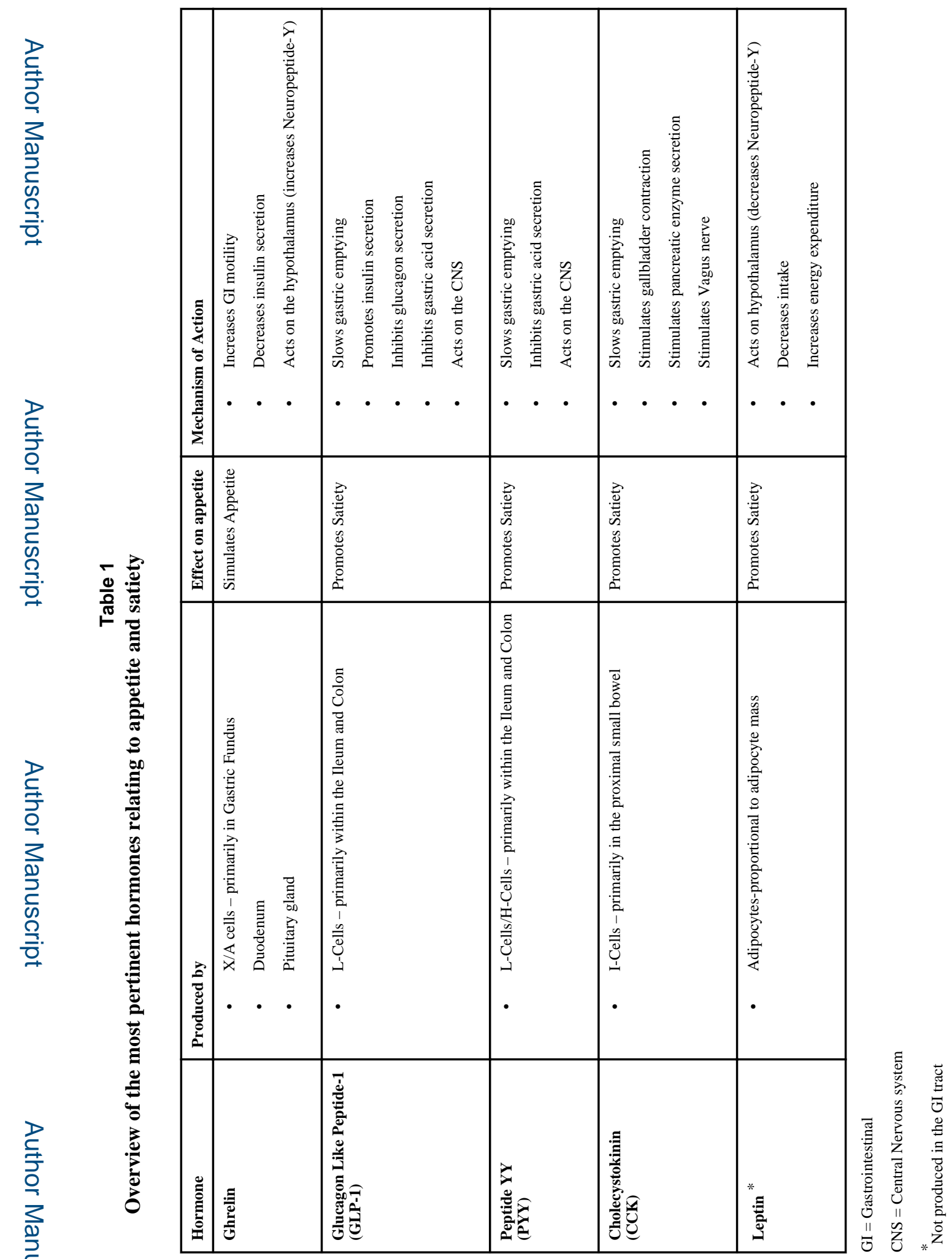

J Vasc Interv Radiol. Author manuscript; available in PMC 2016 May 01. 